\title{
Comparison of Different Techniques in Breast Cancer Radiotherapy Planning
}

F. Gülşen Kara ${ }^{1}$, Ayfer Haydaroğlu ${ }^{1}$, Hakan Eren ${ }^{1}$, Gül Kitapçıŏglu ${ }^{2}$

${ }^{1}$ Department of Radiation Oncology, Ege University Faculty of Medicine, İzmir, Turkey

${ }^{2}$ Department of Biostatistics and Health Informatics, Ege University Faculty of Medicine, İzmir, Turkey

\section{ABSTRACT}

Objective: This study aimed to minimize the radiation dose to organs other than the target tissue during adjuvant therapy applied for breast cancer, by using different planning methods.

Materials and Methods: 30 women with T1-2 N1-3 M0 breast cancer were included in the study. Planning was performed using four different methods to the supraclavicular area, internal, and external tangential fields. All planning was done in a virtual environment by and the requested data was obtained. All patients were treated by the 1st method. Method 1: Different isocenter, complete supraclavicular area, breast half beam. Method 2: Different isocenter, half supraclavicular area, breast half beam. Method 3: Single isocenter, half supraclavicular area, breast half beam. Method 4: Different isocenter, supraclavicular area full beam, breast full beam.

Results: Evaluation of PTV values showed a statistically significant reduction in D-max, 110\% and 115\% values by method III. Lower doses in other parameters were not statistically significant.

Conclusion: Based on these results, the application of single isocenter, 3D radiotherapy in breast cancer provides significant advantages especially in PTV and pulmonary dosages.

Key words: Breast cancer, radiotherapy, toxicity

\section{Introduction}

Breast cancer constitutes approximately $26 \%$ of all cancers in women. In the United States, 209 thousand new cases were detected in 2010 (1). Breast cancer incidence increases at a rate of 1-2\% throughout the world and each year approximately one million new cases are diagnosed (1-3). Lifetime risk of developing breast cancer is calculated as 36\% for women living in some western societies (3).

Since the 1990s, breast cancer incidence is increasing while breast cancer mortality rate in all cancers decreased from $36 \%$ to $25 \%$ (1, 2, 4). One of the most important reasons is that the methods used for diagnosis and screening are more efficient as well as the increasing effectiveness of treatment. With the published randomized controlled trials in the 1990s and their long- term results, radiotherapy has become an integral part of treatment for breast cancer. However, following the article stating that breast radiotherapy resulted in increased myocardial infarcts and caused related mortality in 1994, not only effective treatment with radiotherapy but also reducing its toxicity was taken into account (5). The effective use of both the devices and the newly developed planning techniques provide a great advantage in this regard.

This study aimed to minimize the radiation dose to organs other than the target tissue during adjuvant therapy applied for breast cancer, by using different planning methods.

\section{Materials and Methods}

30 patients who received radiotherapy with a diagnosis of breast cancer in our hospital's Department of Radiation Oncology between 2009 and 2011 were included in the study. Patients enrolled in the study had T1-2, N1 -3, M0 disease and breast-conserving surgery (BCS) was applied to all patients. With a standard dose of 50 Gy to the supraclavicular, internal and external tangential areas, Boost therapy was applied to the tumor location as $16 \mathrm{~Gy}$ if the distance to surgical margin was less than $0.5 \mathrm{~cm}$, and as $10 \mathrm{~Gy}$ if it was over 0.5 $\mathrm{cm}$. The treatment was applied at a dose of $2 \mathrm{~Gy}$ per day, five days a week and on weekdays. Radiotherapy was applied after chemotherapy in patients undergoing chemotherapy, while in other patients it was given following surgery. Hormonal therapy was started according to 
menopausal status in hormone receptor positive patients. Tamoxifen was given to hormone-responsive premenopausal patients and postmenopausal patients were started on an aromatase inhibitor.

All drawings and planning were made by a single physician. According to 50 th and 62 nd reports issued by ICRU (The International Commission on Radiation Units and Measurements) the breast tissue was entered as clinical tumor volume (CTV) and the planned target volume (PTV) PTV margin was given as $1 \mathrm{~cm}$, and the skin margin as $0.5 \mathrm{~cm}(6,7)$. Planning was made by using four different methods to supraclavicular area, internal and external tangential fields. Planning was entirely performed in a virtual environment with acquisition of the requested data. All patients were treated by the 1 st method.

\section{Technique I}

Different isocenter, supraclavicular area full, breast half beam: Planning was set as supraclavicular area full beam, and tangential field half beam with different isocenter. In the supraclavicular area, the gantry angles required for extraction of oesophagus out of the field were added. To ensure the tangential and supraclavicular area overlap table and collimator angles were added. To protect the humerus, larynx and the skin, personalized supraclavicular blocks were inserted; for those patients localized in the left breast and come up with high heart doses, heart block was used.

\section{Technique II}

Different isocenter, supraclavicular area half, breast half beam: Planning was set as supraclavicular area half beam, and tangential field half beam with different isocenter. The gantry angle was provided to extract the oesophagus out of the field and to ensure the tangential and supraclavicular area overlap table and collimator angles were added. In patients with location in the left breast and with high heart doses a heart block was used and for protection of the humerus and the skin personalized blocks were applied to the supraclavicular area.

\section{Technique III}

Single isocenter, supraclavicular area half, breast half beam: Planning was set as supraclavicular area half beam, and tangential field half beam with single isocenter. Table and collimator angles were not added to provide field overlap. The gantry angle was provided to extract the oesophagus out of the field. In patients with location in the left breast and with high heart doses a heart block was used and for protection of the humerus and the skin personalized blocks were used to the supraclavicular area.

\section{Technique IV}

Different isocenter, supraclavicular area full beam, breast full beam: Planning was set as supraclavicular area full beam, and tangential field full beam with different isocenter. The gantry angle was provided to extract the oesophagus out of the field, and to ensure the tangential and supraclavicular area overlap table and collimator angles were added. In patients with location in the left breast and with high heart doses a heart block was used and for protection of the humerus and the skin personalized blocks were applied to the supraclavicular area.

Demographic data of all patients, the pathologic and immune histochemical parameters of the specimens were recorded. Then chemotherapy and radiation therapy doses were recorded. For each of the four methods; PTV (maximum dose, minimum dose, mean dose, $110 \%$ field volume and $115 \%$ Gy field volume), lung (maximum dose, minimum dose, mean dose, 5 Gy field volume, 20 Gy field vol- mean dose, 5 Gy field volume and 25 Gy field volume and mean dose while left breast was unblocked), the left coronary artery (maximum, minimum and mean doses), brachial plexus (maximum, minimum, mean doses and 60 Gy field volume), oesophagus (maximum, minimum, mean doses and 50 and 60 Gy field volumes), as well as mean doses for supraclavicular, level 1, level 2 and level 3 were calculated.

\section{Statistical Analysis}

The data were entered into an electronic database. Statistical software package was used for data analysis (SPSS 18.0). Descriptive analyzes were stated as mean, standard deviation, minimum and maximum values and descriptive tables were created. In further analysis, for the significance of the difference between means the two-way analysis of variance (ANOVA) was performed. Bonferroni test was used for confirmatory analysis. $\mathrm{p}<0.05$ was considered significant.

\section{Results}

The youngest patient was 23 and the oldest 71 years old, the mean age was 49 years. Only one patient $(3.3 \%)$ was premenopausal, whereas 15 (50\%) patients had a natural menopause and 14 (46.3\%) had chemotherapy induced menopause. The general demographic characteristics of the patients are shown in Table 1 .

$60 \%$ of patients $(n=18)$ underwent axillary dissection. Sentinel lymph node biopsy was performed in the remaining 12 patients and in seven and axillary lymph node dissection was added.

The tumor was adjacent to the surgical margin in one patient. The farthest surgical margin was $2 \mathrm{~cm}$. The mean surgical margin distance was $0.53 \mathrm{~cm}$. The smallest tumor diameter was $0.5 \mathrm{~cm}$ and the largest was $3.5 \mathrm{~cm}$, with a mean of $2 \mathrm{~cm}$. The mean number of dissected nodes was 14 (3-33) and the mean number of metastatic nodes was 2 (0-10). The pathological examination revealed invasive ductal carcinoma in the majority of patients $(n=17)$.

All patients received chest wall irradiation together with the supraclavicular area. 50 Gy radiotherapy was applied in all patients, in one patient 47 Gy was given with increase in boost dose. Boost dose was applied to all patients except one patient. The boost dose was $10 \mathrm{~Gy}$ in 15 patients, 13 Gy in 16 patients and 17 Gy in one patient who is mentioned above.

It was shown that the significant difference obtained by the Benforroni approach was caused by method III. On evaluation of the PTV values, D- $\max (\mathrm{p}=0.006), 110 \%(\mathrm{p}<0.0001)$ and $115 \%(\mathrm{p}<0.0001)$ values had a statistically significant reduction in method III. The lowest dose values regarding other parameters (PTV min, mean PTV) were also obtained by method III, although this difference did not reach statistical significance. Regarding pulmonary doses, there was also a statisti-

\section{Table 1. Patient demographics}

\begin{tabular}{|lcccc}
\hline Feature & Minimum & Maximum & Mean & $\begin{array}{c}\text { Standard } \\
\text { deviation }\end{array}$ \\
\hline Age (year) & 23 & 71 & 48.9 & 11.4 \\
\hline Weight $(\mathrm{kg})$ & 46 & 106 & 73.7 & 12.2 \\
\hline Height $(\mathrm{cm})$ & 145 & 168 & 157.6 & 2.9 \\
\hline BMl $(\mathrm{kg} / \mathrm{m} 2)$ & 19.4 & 40.4 & 29.9 & 5.2 \\
\hline BMl: Body mass index & & & \\
\hline
\end{tabular}


cally significant decrease in V5 $(\mathrm{p}=0.005)$. However, although lower values in favor of method III were obtained in V25, V20, D- mean and D-min, the highest value for Dmax was also obtained in this method. The evaluated cardiac values of V25, V5, D- max, and D- min have also decreased in a similar manner in favor of method III. Nevertheless, the highest D-min value was observed in method III. The evaluation of LAD showed a reduction in D-max and D-mean doses in method III, although not statistically significant, while the D-min value did not show superiority over other methods. The V60 value calculated for the brachial plexus was equal to zero in all methods. D-max, D-min and $\mathrm{D}$ - mean values showed very small non-significant differences. The V60 value calculated for the esophagus was equal to zero in all methods. The V50, D-max, D-min and D-mean values were found to be lower in favor of method III, although not statistically significant. The evaluation for conformity index showed no significant difference, in fact the obtained values were very close to each other. Similarly, significant difference was not detected in dose assessments of the supraclavicular area, level I, II and III.

During radiotherapy in patients with left breast cancer, cardiac doses was reduced almost by half by use of lead alloy blocks to protect the heart.

\section{Discussion and Conclusions}

Frequently encountered in women, breast cancer is still a serious problem due to both incidence and mortality rates. It has been shown that radiotherapy, which is accepted as an integral part of breast-conserving surgery, improves survival by reducing local recurrence in locally advanced breast cancer (8).

Although radiation therapy is applied with success nowadays, especially in recent years, adverse effects and side effects of radiotherapy are being discussed frequently (9). The aim is to both irradiate the targeted area with the appropriate amount of radiation and protect other organs from radiation, and if possible not receive any dose at all.

While planning radiotherapy after BCS, the remaining breast tissue, chest wall, and incision area are included in the irradiation field (10). Depending on the patient's lymph node metastasis, the axilla or supraclavicular area is included in the area to be irradiated $(11,12)$. The total dose applied to the breast should be 45-50 Gy in 5-6 weeks. In our patients after 50 Gy whole breast irradiation, all patients received an additional dose of $16 \mathrm{~Gy}$ if the closest surgical margin was less than $0.5 \mathrm{~cm}$ and $10 \mathrm{~Gy}$ if more distant.

Various methods such as 2D planning, 3D planning, IMRT, IGRT, Field in Field, have been described to be applied in breast cancer radiotherapy planning with developing technological infrastructure and software programs $(13,14,15)$. Among these combinations with methods like single isocenter, multiple isocenter, half- beam, or full beam are generated $(16,17)$. Although application methods continuously improve with developments in technology, there is not an accepted standard method $(18,19,20)$. The most commonly used methods are $3 \mathrm{D}$ planning and IMRT planning $(21,22)$. By these two commonly used methods better dose homogenisation is provided with significant reduction in especially skin toxicity and minimizing the dose received by normal organs. However, there is insufficient data on long-term results. In our clinic, 3D supraclavicular area full beam, tangential areas half beam, two-isocentric treatment is applied. A significant problem with treatment using different isocenters is undesirably increased doses due to overlapping of fields. At this point, the use of a single isocenter seems to be a suitable solution. However, in the literature we did not find a study comparing one and two- isocenter 3D planning. By simple logic, the most practical and precise way of eliminating intersection of two areas is to decrease two fields to one. The PTV values in our study support this conclusion. The PTV max and PTV mean values obtained by single isocenter use were very close to the planned values and overdose was minimal. The advantage in PTV max was statistically significant $(\mathrm{p}=0.006)$. Single isocenter use resulted in more than half reduction in PTV 110\% and PTV 115\% values as compared to multiple isocenter (regardless of full beam or half beam status) planning and this reduction was statistically significant $(\mathrm{p}<0.0001)$.

Lungs are one of the first organs to receive radiation beam and to be protected during breast radiation (23). The pulmonary damage ranges from simple edema to severe pneumonia and fibrosis. The severity of symptoms is often directly proportional with the disease $(23,24) .3 \mathrm{D}$ and IMRT planning provides significant advantages in the prevention radiation pneumonitis (25). The values obtained in our study in $3 \mathrm{D}$ planning were similar to the literature, although the superiority of single isocenter use could not be clearly demonstrated (24). However, statistically significant reduction of V5 was detected (0.005). There was a decrease in V20, V25, and D- mean values but they did not reach statistical significance. Nevertheless, the relative surplus in D- max and D-min values as compared to other methods precludes a final judgment. Still, the positive results obtained in other doses are promising.

Another important organ affected during breast radiation is the heart. Although the exact mechanism is not clear, the dose of radiation exposure causes significant cardiac toxic effects (26) and results in significant mortality (27). These risks are increased especially during radiotherapy for the left breast $(26,27)$. Patient related factors like gender, age, diabetes, smoking habits, hypertension, obesity, and hypercholesterolemia contribute significantly to these risks, still the most important factor is the dose received by the heart $(26,27)$. The most important study on cardiac dose affecting the heart was published by Shultz-Hector (28). In this study conducted in 2007 , it has been reported that doses as low as 1-2 Gy may cause acute effects and cardiac mortality could be observed at a dose of approximately 10Gy. The emerging devices and new contouring techniques are highly effective in better cardiac dose calculation and reduction $(26,27)$. In recent studies, IMRT and 3D planning radiation therapy is reported to provide for the lowest cardiac dose (29). There is not any study stating the cardiac dose caused by treatments using different isocenters, as in the lung. In our study, the doses obtained were generally similar to the literature, single isocenter application resulted in significant reduction, although not statistically significant. There was an approximately $25 \%$ decrease in V25, V5, D- mean, D-min and D- max values as compared to the other methods that use multiple isocenters, although it was not statistically significant. Similar results were obtained from the measurements for the left coronary artery.

During radiotherapy planning for breast cancer, another area to be considered and protected as much as possible is the brachial area. As the dose administered increases, the risk of damage also increases (30). Some patients may require surgical decompression and in unnoticed or untreated cases, permanent damage may occur (30). In the literature brachial plexus injury is mentioned in most studies, however we were unable to find a detailed study regarding the results of dose measurements specific to this field. In our study, doses corresponding to this area in each of the four methods did not show a statistical difference, in fact, the doses were almost equal. Similarly, in a study with single isocenter $3 \mathrm{D}$ planning, a slight decrease in dose has been reported that 
did not reach significance (31). In parallel, any significant difference between the calculated values for the close located supraclavicular area was also not found.

Another organ to be taken into account during planning and dose calculation is the esophagus. The doses obtained in each of the four methods, including the maximal doses, are well below the recommended tolerance dose by Emami (32). Although it has been reported that the maximum dose received by the esophagus is decreased $50 \%$ by using the single isocenter 3D planning, in our study, a marked difference in V50 could only be achieved in planning that use complete bundle (31). When half beam was used, in both the supraclavicular and tangential field, almost the same results were obtained even if different isocenters were taken into account. Moreover, the difference detected with other methods was not statistically significant. The D- mean, D- max and D- min values were nearly equal.

The conformity index was first published by the RTOG in ICRU 62 in 1993 (7). After the publication of this report, conformity index was considered more often in radiotherapy planning. In our study, the conformity index in each of the four methods did not show a significant difference.

In our study, it has been detected that the advantages obtained in PTV max and the reduction in PTV $110 \%$ and PTV 115\% values in single isocenter application are statistically significant $(\mathrm{p}<0.0001)$. On evaluation of pulmonary doses, there was a statistically significant reduction in V5. In addition, although not reaching statistical significance, a marked decrease was achieved in lung V20, V25, D-mean doses and doses received by the heart. Similar results were obtained from measurements for the left coronary artery. No significant differences were found in brachial plexus, esophagus and supraclavicular area doses.

Based on these results, the application of single isocenter, 3D radiotherapy planning in breast cancer provides significant advantages especially in PTV and pulmonary doses.

\section{Ethics Committee Approval: N/A.}

Conflict of Interest: No conflict of interest was declared by the authors.

Peer-review: Externally peer-reviewed.

\section{Informed Consent: N/A.}

Author Contributions: Concept - F.G.K., A.H.; Design - F.G.K., A.H.; Supervision - F.G.K., A.H.; Funding - F.G.K., H.E.; Materials F.G.K., H.E.; Data Collection and/or Processing - F.G.K., H.E.; Analysis and/or Interpretation - F.G.K., G.K.; Literature Review - F.G.K., A.H.; Writer - F.G.K., A.H.; Critical Review - F.G.K., A.H.

Financial Disclosure: The authors declared that this study has received no financial support.

\section{References}

1. Cancer fact \& figures 2010. Available from: URL: http://www.cancer.org/ acs/groups/content/@epidemiologysurveilance/documents/document/ acspc-026238.pdf.

2. SEER cancer statistics 1975-2008. Available from: URL: http://seer. cancer.gov/csr/1975_2008/browse_csr.php?section $=48$ page =sect_04_table.12.html.
3. World health statistics 2010. World Health Organization 2011. Available from: URL: http://www.who.int/whosis/whostat/EN_WHS10_Full.pdf.

4. Boring CC, Squires TS, Tong T. Cancer statistics 1993. Cancer J Clin 1993; 43:4-26. (PMID: 8422609)

5. Cuzick J, Stewart H, Rutqvist L, Houghton J, Edwards R, Redmond C, Peto R, Baum M, Fisher B, Host H. Cause-specific mortality in long-term survivors of breast cancer who participated in trials of radiotherapy. Clin Oncol 1994; 12:447-453. (PMID: 8120544)

6. Prescribing, Recording and Reporting Photon Beam Therapy (Report62). Available from: URL: http://www.icru.org/index.php?option=com_ content\&task=view\&id=60.

7. Prescribing, Recording, and Reporting Photon Beam Therapy (Report50). Available from: URL: http://www.icru.org/index.php?option=com_conte nt\&task=view\&id=72\&Itemid $=9$

8. Early Breast Cancer Trialists' Collaborative Group: Favorable and unfavorable effects on long term survival of radiotherapy for early breast cancer. Lancet 2000; 355:1757-1770. (PMID: 10832826) [CrossRef]

9. Muren LP, Maurstad G, Hafslund R, Anker G, Dahl O. Cardiac and pulmonary doses and complication probabilities in standard and conformal tangential irradiation in conservative management of breast cancer. Radiother Oncol 2000; 62:173-183. (PMID: 11937244) [CrossRef]

10. Fong A, Bromley R, Beat M, Vien D, Dineley J, Morgan G. Dosimetric comparison of intensity modulated radiotherapy techniques and standard wedged tangents for whole breast radiotherapy. J Med Imaging Radiat Oncol 2009; 53:92-99. (PMID: 19453534) [CrossRef]

11. Thilmann C, Zabel A, Nill S, Rhein B, Hoess A, Haering P, Milke-Zabel S, Harms W, Schlegel W, Wannenmacher M, Debus J. Intensity-modulated radiotherapy of the female breast. Med Dosim 2002; 27:79-90. (PMID: 12074472) [CrossRef]

12. Ohashi T, Takeda A, Shigematsu N, Fukada J, Sanuki N, Amemiya A, Kubo A. Dose distribution analysis of axillary lymph nodes for threedimensional conformal radiotherapy with a field-in-field technique for breast cancer. Int J Radiat Oncol Biol Phys 2009; 73:80-87. (PMID: 18602764) [CrossRef]

13. Livi L, Buonamici FB, Simontacchi G, Scotti V, Fambrini M, Compagnucci A, Paiar F, Scoccianti S, Pallotta S, Detti B, Agresti B, Talamonti C, Mangoni M, Bianchi S, Cataliotti L, Marrazzo L, Bucciolini M, Biti G. Accelerated partial breast irradiation with IMRT: new technical approach and interim analysis of acute toxicity in a phase III randomized clinical trial. Int J Radiat Oncol Biol Phys 2010; 77:509-515. (PMID: 19700248) [CrossRef]

14. Schubert LK, Gondi V, Sengbusch E, Westerly DC, Soisson ET, Paliwal BR, Mackie TR, Mehta MP, Patel RR, Tomé WA, Cannon GM. Dosimetric comparison of left-sided whole breast irradiation with 3DCRT, forward-planned IMRT, inverse-planned IMRT, helical tomotherapy, and topotherapy. Radiother Oncol 2011; 100:241-246. (PMID: 21316783) [CrossRef]

15. Lee JW, Hong S, Choi KS, Kim YL, Park BM, Chung JB, Lee DH, Suh TS. Performance evaluation of field-in-field technique for tangential breastirradiation. Jpn J Clin Oncol 2008; 38:158-163. (PMID: 18216025) [CrossRef]

16. Leonard L. Gunderson, Joel E. Tepper Clinical radiation oncology. Philedelphia: Churchill Livingstone, 2007:140-141.

17. Seymour H. Levitt Technical Basis of Radiation Therapy: Practical Clinical Applications. Berlin: Springer, 2006:70-71.

18. Donovan E, Bleakley N, Denholm E, Evans P, Gothard L, Hanson J, Peckitt C, Reise S, Ross G, Sharp G, Symonds-Tayler R, Tait D, Yarnold J; Breast Technology Group. Randomised trial of standard 2D radiotherapy (RT) versus intensity modulated radiotherapy (IMRT) in patients prescribed breast radiotherapy. Breast Technology Group. Radiother Oncol 2007; 82:254-264. (PMID: 17224195) [CrossRef]

19. Webb $S$. The physical basis of IMRT and inverse planning. Br J Radiol 2003; 76:678-689. (PMID: 14512327) [CrossRef]

20. Fong A, Bromley R, Beat M, Vien D, Dineley J, Morgan G. Dosimetric comparison of left-sided whole breast irradiation with 3DCRT, forward-planned IMRT, inverse-planned IMRT, helical tomotherapy, and 
topotherapy. J Med Imaging Radiat Oncol 2011; 100:241-246. (PMID: 19453534)

21. Ohashi T, Takeda A, Shigematsu N, Fukada J, Sanuki N, Amemiya A, Kubo A. Dose distribution analysis of axillary lymph nodes for threedimensional conformal radiotherapy with a field-in-field technique for breast cancer. Int J Radiat Oncol Biol Phys 2009; 73:80-87. (PMID: 21316783) [CrossRef]

22. Vicini F, Winter K, Wong J, Pass H, Rabinovitch R, Chafe S, Arthur D, Petersen I, White J, McCormick B. Initial efficacy results of RTOG0319: three-dimensional conformal radiation therapy (3D-CRT) confined to the region of the lumpectomy cavity for stage I/II breast carcinoma. Int J Radiat Oncol Biol Phys 2010; 77:1120-1127. (PMID: 19910132) [CrossRef]

23. Marks LB, Bentzen SM, Deasy JO, Kong FM, Bradley JD, Vogelius IS, El Naqa I, Hubbs JL, Lebesque JV, Timmerman RD, Martel MK, Jackson A. Radiation dose-volume effects in the lung. Int J Radiat Oncol Biol Phys 2010;76:70-76. (PMID: 20171521) [CrossRef]

24. Teh AY, Park EJ, Shen L, Chung HT. Three-dimensional volumetric analysis of irradiated lung with adjuvant breast irradiation. Int J Radiat Oncol Biol Phys 2009; 75:1309-1315. (PMID: 19427749) [CrossRef]

25. Rudat V, Alaradi AA, Mohamed A, Ai-Yahya K, Altuwaijri S. Tangential beam IMRT versus tangential beam 3D-CRT of the chest wall in postmastectomy breast cancer patients: A dosimetric comparison. Radiat Oncol 2011; 6:26. (PMID: 21418616) [CrossRef]
26. Marks LB, Yu X, Prosnitz RG, Zhou SM, Hardenbergh PH, Blazing M, Hollis D, Lind P, Tisch A, Wong TZ, Borges-Neto S. The Incidence and Functional Consequences of RT-associated cardiac perfusion defects. Int J Radiat Oncol Biol Phys 2005; 63:214-223. (PMID: 16111592) [CrossRef]

27. Gagliardi G, Constine LS, Moiseenko V, Correa C, Pierce LJ, Allen AM, Marks LB. Radiation dose-volume effects in the heart. Int J Radiat Oncol Biol Phys 2010; 76:77-85. (PMID: 20171522) [CrossRef]

28. Schultz-Hector S, Trott KR. Radiation-induced cardiovascular diseases: is the epidemiologic evidence compatible with the radiobiologic data? Int J Radiat Oncol Biol Phys 2007, 67:10-18. (PMID: 17189062) [CrossRef]

29. Pignol JP, Keller BM, Ravi A. Doses to internal organs for various breast radiation techniques--implications on the risk of secondary cancers and cardiomyopathy. Radiat Oncol 2011; 6:5. (PMID: 21235766) [CrossRef]

30. Gosk J, Rutowski R, Urban M, Wiecek R, Rabczyński J. Brachial plexus injuries after radiotherapy - analysis of 6 cases. Folia Neuropathol 2007; 45:31-35. (PMID: 17357009)

31. Van Beek S, De Jaeger K, Mijnheer B, Van Vliet-Vroegindeweij C. Evaluation of a single-isocenter technique for axillary radiotherapy in breast cancer. Med Dosim 2008; 33:191-198. (PMID: 18674683) [CrossRef]

32. Emami B, Lyman J, Brown A, Coia L, Goitein M, Munzenrider JE, Shank B, Solin LJ, Wesson M. Tolerance of normal tissue to therapeutic irradiation. Int J Radiat Oncol Biol Phys 1991;21:109-122. (PMID: 2032882) [CrossRef] 